\title{
Surgical and non-surgical education practices in female pelvic medicine and reconstructive surgery fellowships within the United States
}

\author{
John A. Occhino ${ }^{1 *}$, Eilean L. Myer ${ }^{1}$, Ruchira Singh ${ }^{2}$, John B. Gebhart ${ }^{1}$ \\ ${ }^{1}$ Department of Obstetrics and Gynecology, Mayo Clinic, Rochester, USA \\ ${ }^{2}$ Department of Obstetrics and Gynecology, Hurley Medical Center, Michigan State University College of Human Medicine, Flint, \\ USA \\ Email: ${ }^{*}$ occhino.john@mayo.edu
}

Received 9 March 2013; revised 10 April 2013; accepted 17 April 2013

Copyright (C) 2013 John A. Occhino et al. This is an open access article distributed under the Creative Commons Attribution License, which permits unrestricted use, distribution, and reproduction in any medium, provided the original work is properly cited.

\begin{abstract}
Data are scarce regarding surgical and non-surgical education in accredited Female Pelvic Medicine and Reconstructive Surgery (FPMRS) fellowships in the United States. We compared surgical and non-surgical and education among training programs and expected surgical comfort level with pelvic reconstructive procedures from the perspective of the fellow and program director. An online survey was distributed to program directors and fellows from the $\mathbf{3 9}$ accredited FPMRS fellowships at the time (2010). Domains evaluated in the survey were academic education requirements; surgical approaches to prolapse and to incontinence; other surgical procedures; and research and publication expectations. In total, forty fellows from 21 programs and directors from 27 programs responded. The most common surgical procedures performed for apical, anterior, and posterior prolapse were uterosacral ligament suspension, native tissue anterior colporrhaphy, and posterior colporrhaphy, respectively. Differences in perceived surgical comfort level were seen for coccygeus suspension, graftreinforced posterior colporrhaphy, rectus fascial sling, urethral bulking agent, cystoscopic ureteral stent placement and bowel repair. A greater proportion of program directors reported that fellows would be comfortable performing these procedures upon graduation than the proportion reported by the fellows themselves. Differences exist in FPMRS training nationwide, however, responding fellows appeared to be trained in multiple approaches to prolapse repair. Differences were seen in surgical comfort level as perceived by fellows and program directors.
\end{abstract}

${ }^{*}$ Corresponding author.
Keywords: Education; Fellowship; Female Pelvic Medicine and Reconstructive Surgery; Surgical Procedures; Training

\section{INTRODUCTION}

Training across surgical specialties has seen considerable change over the past decade. With the introduction of duty-hour restrictions in the United States, the increasing popularity and capabilities of surgical simulation, and the shift toward subspecialization, the environment in which residents and fellows acquire surgical knowledge provides many new challenges [1,2]. A movement away from a solely apprenticeship model to an integrated model that incorporates various educational modalities is expected to be the way of the future $[3,4]$. Such training likely will include laparoscopy simulation, surgical case evaluation, and didactic learning, because educational objectives are now required to include both technical skill and non-surgical patient treatment $[5,6]$. In the realm of gynecologic surgery, 2 major recognized fellowships have emerged: gynecologic oncology and female pelvic medicine and reconstructive surgery (FPMRS), commonly termed as urogynecology.

Since 2005, several studies have investigated FPMRS training from various points of view. However, these studies have focused primarily on the perspectives of obstetrics and gynecology residents and the residency program director, with limited evaluation of the FPMRS fellow themselves $[7,8]$. Overall, investigators have concluded that resident surgical training in a number of common pelvic reconstructive procedures is insufficient for independent surgical practice post residency $[7,9]$. Currently, little data are available regarding FPMRS fellows' and fellowship program directors' perspectives on 
surgical and non-surgical education and proficiency.

Certain core competencies are required for FPMRS fellowship program accreditation in the United States, such as surgical and non-surgical management of pelvic organ prolapse and urinary incontinence, education in pelvic anatomy and physiology, and coursework in statistics and epidemiology [10,11]. The approach to surgical correction of pelvic organ prolapse may vary substantially from program to program. There is yet to be standardization in surgical training and therefore variations among training programs may include a preference toward vaginal native tissue repair, vaginal repair with graft augmentation, use of prefabricated mesh kits, laparoscopic and robotic approaches, and open abdominal approach. We believe that graduating fellows are trained in the management of a variety of pelvic floor disorders, but we are seeking information on the predominant techniques taught by different programs for the management of these problems. Surgical training in FPMRS currently faces a time of marked change, with the recent recognition of the subspecialty by the American Board of Medical Subspecialties and institution of a formalized process for board certification. The objective of this study was to evaluate similarities and differences in surgical and nonsurgical education among accredited FPMRS fellowships in the United States and examine expected surgical comfort level of fellows from the perspective of program directors and fellow themselves.

\section{METHODS}

In February 2010, there were 39 accredited FPMRS fellowship programs listed on the American Board of Obstetrics and Gynecology and American Board of Urology Web sites. A 33-question, internet-based survey was distributed via email to FPMRS program directors from all US accredited American Board of Obstetrics and Gynecology/American Board of Urology FPMRS fellowships. They were contacted by e-mail and asked to participate in the survey. A link to the survey was provided in the e-mail, along with a request for further distribution to their respective fellows, as a comprehensive list of fellow emails was not available. An e-mail reminder was provided to all non-responding fellowship directors and those with non-responding fellows 2 weeks later.

Having fellowship directors and fellows complete the survey allowed for comparison of their responses on identical topics. Information regarding required educational courses, additional degrees, and off-service rotations was obtained solely through program director responses.

Fellow and program director surveys were identical except the fellow survey evaluated expected surgical competence of themselves upon graduation, while the director's survey evaluated expected competence of the fellows upon graduation. Each question was multiple choice with a section for write-in documentation if an answer was not listed (Figure 1). Specifically, the survey evaluated surgical procedure preferences for repair of primary and recurrent pelvic organ prolapse in the anterior, apical, and posterior compartments. Training in laparoscopy and robotics was also addressed. General educational questions included the option or requirement for completion of a master's degree during the fellowship, anticipated number of publications on completion, and required off-service clinical rotations. Career plans after completion of the fellowship were evaluated with respect to planning a career in academics, private practice, or a hybrid of the two areas. The study was approved by the Mayo Clinic Institutional Review Board.

After 1 month, the survey was closed and responses were analyzed. Differences between the perceptions of directors and fellows on various procedures were compared through $\chi^{2}$ or Fisher exact test where appropriate.

\section{RESULTS}

\subsection{Population Characteristics}

Of the 39 accredited FPMRS fellowship programs listed on the American Board of Obstetrics and Gynecology (ABOG) and American Board of Urology (ABU) web sites, 27 program directors (69\%) and 40 fellows (approximately $37 \%$ ) completed the online survey. The estimated number of FPMRS fellows nationwide was 108; however, a comprehensive list was not available through ABOG/ABU. The fellows who responded represented 21 different programs, or $54 \%$ of the 39 accredited programs at the time of the survey. Almost all of the responding fellows (39 (97.5\%)) completed residency training in obstetrics and gynecology. The remaining fellow had a urology background. Fifteen $(37.5 \%)$ were firstyear fellows; 9 (22.5\%), second-year fellows; and 16 $(40.0 \%)$, third-year fellows. Two of the 15 first-year fellows $(12.5 \%)$ had not begun clinical rotations at the time of survey completion, leaving 95\% (38/40) of re- sponding fellows having fellowship clinical experience.

\subsection{Surgical Training}

Responses from fellows were used to determine the most common surgical procedures for treatment of pelvic organ prolapse. Apical compartment prolapse was most commonly treated with transvaginal uterosacral ligament suspension followed secondly by sacrocolpopexy (Figure 2(a)). Anterior and posterior compartment prolapses were most commonly treated with colporrhaphy (Figures 2(b) and (c)). Midurethral sling was the most common treatment for stress urinary incontinence, with $80 \%$ of fellows primarily using retropubic slings and $20 \%$ using transobturator slings (Figure 2(d)). The median 
number of surgeries performed per week by the fellow as ever, this number varied from the category " 0 - 2 " to the primary surgeon was 3 to 5 per compartment; how-

" $\geq 9$ " (Figure 3). Fellows were asked which procedures

\begin{tabular}{|c|c|c|}
\hline \multirow{4}{*}{$\begin{array}{c}\text { Urogyn Fellowship Education } \\
\text { Fellows Survey }\end{array}$} & \multirow{2}{*}{$\begin{array}{l}\text { Abdominal sacrocolpopexy } \\
\text { Graft reinforced colporrhaphy }\end{array}$} & Intravesical botox injection \\
\hline & & Bladder installations \\
\hline & Transvaginal mesh kit & Other (please specify) \\
\hline & Other (please specify) & 25. Which of the following OTHER procedures do you \\
\hline 1. In what field did you complete residency training? & $\begin{array}{l}\text { 14. Which of the following procedures for POSTERIOR } \\
\text { compartment prolapse do you expect to feel comfortable }\end{array}$ & $\begin{array}{l}\text { actively participate in during your fellowship? Select all that } \\
\text { apply: }\end{array}$ \\
\hline Obstetrics and Gynecology & performing independently upon completion of fellowship? & Pessary fitting \\
\hline Urology & Select all that apply: & Cystotomy closure \\
\hline \multirow{2}{*}{$\begin{array}{l}\text { 2. If Urology, did you perform hysterectomies as part of your } \\
\text { residency training? }\end{array}$} & Posterior colporrhaphy & Cystoscopic Ureteral stent placement \\
\hline & Abdominal sacrocolpopexy & Cystoscopic Ureteral stent removal \\
\hline Yes No & Graft reinforced colporrhaphy & Ureteral repair (ureteroneocystostomy, ureteroureterostomy) \\
\hline 3. What year of fellowship are you currently in? & Transvaginal mesh kit & Bowel surgery/repair \\
\hline $1 \quad 2 \quad 3$ & Other (please specify) & Rectovaginal fistula repair \\
\hline \multirow{2}{*}{$\begin{array}{l}\text { 4. If this is your first year of fellowship, have you started } \\
\text { clinical rotations? }\end{array}$} & 15. In an average week, approximately how many & Vesicovaginal fistula repair \\
\hline & procedures for POSTERIOR compartment prolapse are you & 26. Which of the above OTHER procedures do you expect to \\
\hline Yes $\quad$ No & the primary surgeon? & feel comfortable performing independently upon completion \\
\hline \multirow{2}{*}{$\begin{array}{l}\text { 5. Which formal academic classes do you take as part of } \\
\text { your fellowship? Select all that apply: }\end{array}$} & $\begin{array}{llll}0-2 & 3-5 & 6-8 & >9\end{array}$ & of fellowship? Select all that apply: \\
\hline & 16. What is the most common procedure used to treat & Pessary fitting \\
\hline Epidemiology & STRESS URINARY INCONTINENCE at your institution? & Cystotomy closure \\
\hline Statistics & Retropubic synthetic sling & Cystoscopic Ureteral stent placement \\
\hline Research protocol development & Transobturator synthetic sling & Cystoscopic Ureteral stent removal \\
\hline Anatomy & Mini sling (any type) & Ureteral repair (ureteroneocystostomy, ureteroureterostomy) \\
\hline Ethics Other (please specify) & Burch retropubic urethropexy & Bowel surgery/repair \\
\hline 6. Is a Masters or other graduate level degree offered as part & Rectus fascia sling & Rectovaginal fistula repair \\
\hline of your fellowship? & Bulking agent & Vesicovaginal fistula repair \\
\hline Yes $\quad$ No & Other (please specify) & 27. Which "OFF SERVICE" rotations are part of your \\
\hline If Yes, what degree type(s)? & 17. Which of the following procedures for STRESS URINARY & fellowship? Select all that apply: \\
\hline $\begin{array}{l}\text { 7. What is the most common procedure used to treat } \\
\text { APICAL compartment prolapse at your institution? }\end{array}$ & $\begin{array}{l}\text { INCONTINENCE do you expect to feel comfortable } \\
\text { performing independently upon completion of fellowship? }\end{array}$ & 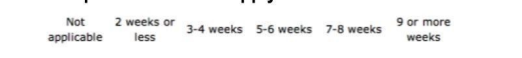 \\
\hline Abdominal sacrocolpopexy & $\begin{array}{l}\text { perrorming indepenaentiy upon completion or rellowsip? } \\
\text { Select all that apply: }\end{array}$ & Urogynecology \\
\hline Sacrospinous ligament fixation & Retropubic synthetic sling & (if Urology based program) \\
\hline Uterosacral ligament suspension & Transobturator synthetic sling & Urology \\
\hline Transvaginal mesh kit & Mini sling (any type) & Colon \& Rectal Surgery \\
\hline Other (please specify) & Burch retropubic urethropexy & Gastroenterology \\
\hline 8. Which of the following procedures for APICAL & Rectus fascia sling & Physical Medicine and Rehabilitation \\
\hline compartment prolapse repair do you expect to feel & Bulking agent & Geriatrics \\
\hline comfortable performing independently upon completion of & Other (please specify) & Intensive Care Unit \\
\hline fellowship? Select all that apply: & 18. In an average week, approximately how many & Plastic Surgery \\
\hline Abdominal sacrocolpopexy & procedures for STRESS URINARY INCONTINENCE are you & General Surgery \\
\hline Sacrospinous ligament fixation & the primary surgeon? & Gynecologic Oncology \\
\hline Uterosacral ligament suspension & $\begin{array}{llll}0-2 & 3-5 & 6-8 & >9\end{array}$ & Other (please specify) \\
\hline Transvaginal mesh kit & 19. Are you trained in ROBOTIC surgery during your & 28. Are there any "OFF SERVICE" rotations not offered \\
\hline Other (please specify) & fellowship? & during your fellowship that you believe would be of benefit \\
\hline 9. In an average week, approximately how many procedures & Yes No & to you? Select all that apply: \\
\hline $\begin{array}{l}\text { for APICAL compartment prolapse are you the primary } \\
\text { surgeon? }\end{array}$ & $\begin{array}{l}\text { 20. If Yes, which of the following ROBOTIC procedures do } \\
\text { you expect to feel comfortable performing independently }\end{array}$ & \\
\hline $0-2 \quad 3-5 \quad 6-8 \quad>9$ & upon completion of fellowship? Select all that apply: & Urogynecology(if Urology based program) \\
\hline 10. What is the most common procedure used to treat & Hysterectomy & Urology \\
\hline ANTERIOR compartment prolapse at your institution? & Sacrocolp & Colon \& Rectal Surgery \\
\hline Anterior colporrhaphy & Burch retropubic urethropexy & Gastroenterology \\
\hline Abdominal sacrocolpopexy & 21. Are you trained in LAPAROSCOPIC surgery, not & Physical Medicine and Rehabilitation \\
\hline Graft reinforced colporrhaphy & including robotics, during your fellowship? & Geriatrics Intensive Care Unit \\
\hline Transvaginal mesh kit & Yes No & Plastic Surgery \\
\hline Paravaginal defect repair & 22. If Yes, which of the following LAPAROSCOPIC & General Surgery \\
\hline Other (please specify) & procedures do you expect to feel comfortable performing & Gynecologic Oncology \\
\hline 11. Which of the following procedures for ANTERIOR & independently upon completion of fellowship? Select all that & Other (please specify) \\
\hline compartment prolapse do you expect to feel comfortable & apply: & 29. What is the approximate number of publications you \\
\hline performing independently upon completion of fellows & Hysterectomy & expect to complete during your fellowship? \\
\hline Select all that apply: & Sacrocolpopexy & 3 or less $\quad 4-7 \quad 8-10 \quad$ Greater than 10 \\
\hline Anterior colporrhaphy & Burch retropubic urethropexy & 30. Do you provide obstetrical services during your \\
\hline Abdominal sacrocolpopexy & 23. What surgical therapies are you using to treat & fellowship commitment? \\
\hline Graft reinforced colporrhaphy & REFRACTORY URGENCY, FREQUENCY AND URGE & Yes No \\
\hline Transvaginal mesh kit & INCONTINENCE? Select all that apply: & 31. If Yes, select all that apply: \\
\hline Paravaginal defect repair & Sacral nerve stimulation & Required institution call \\
\hline Other (please specify) & Intrave & Optional institution call \\
\hline 12. In an average week, approximately how many & Bladder installations & Locum \\
\hline procedures for ANTERIOR compartment prolapse are you & Other (please specify) & 32. What are your expectations for employment upon \\
\hline the primary surgeon? & 24. Which of the following procedures for REFRACTORY & completion of fellowship? \\
\hline $0-2 \quad 3-5 \quad 6-8 \quad>9$ & URGENCY, FREQUENCY AND URGE INCONTINENCE do you & Academic \\
\hline 13. What is the most common procedure used to treat & expect to feell comfortable performing independently upon & Private practice \\
\hline POSTERIOR compartment prolapse at your institution? & completion of fellowship? Select all that apply: & Hybrid of Academic and Private Practice \\
\hline Posterior colporrhaphy & Sacral nerve stimulation & 33. In which fellowship program are you currently enrolled? \\
\hline
\end{tabular}

Figure 1. Copy of the fellowship education survey. 


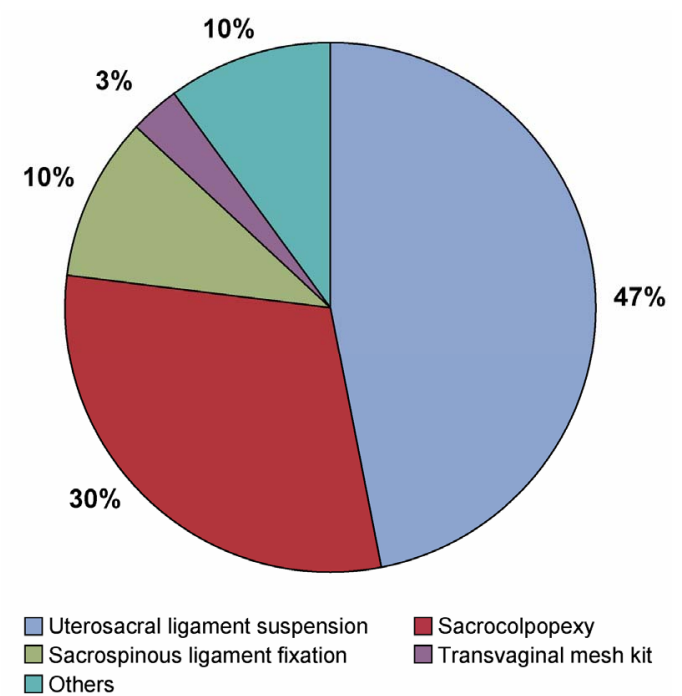

(a)

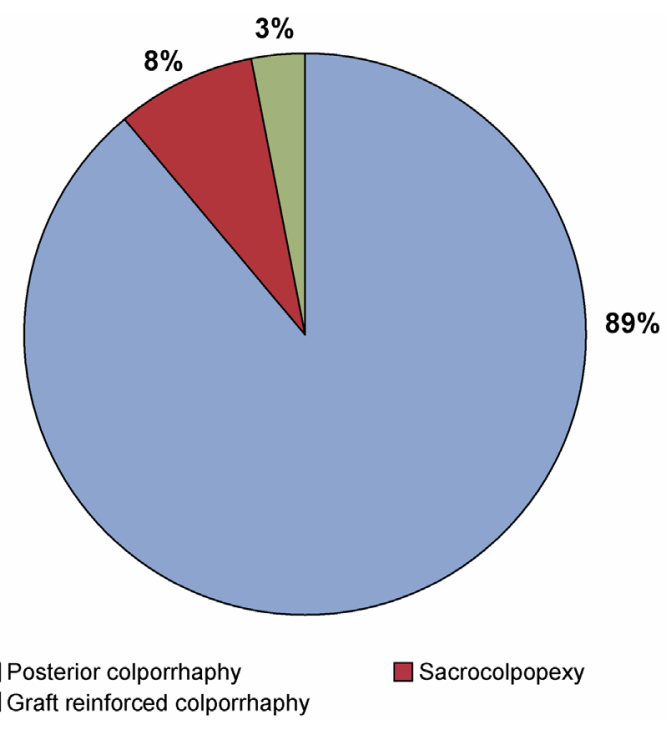

(c)

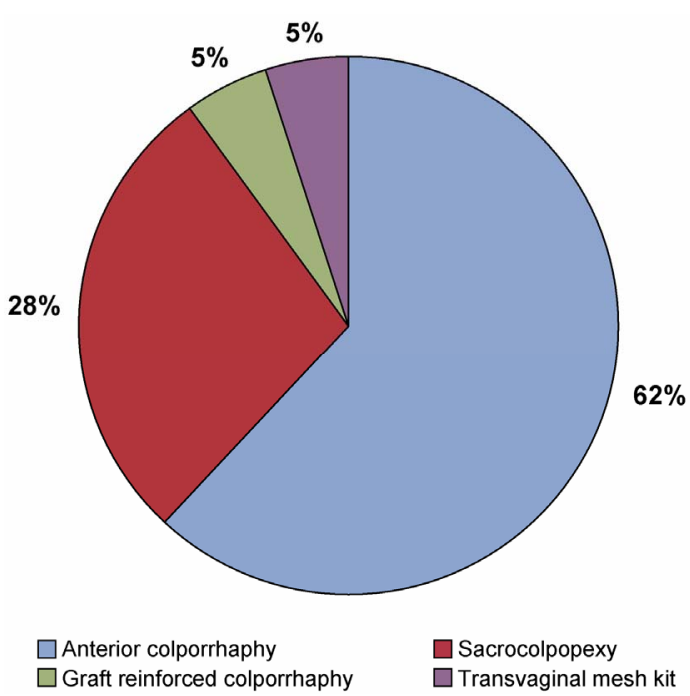

(b)

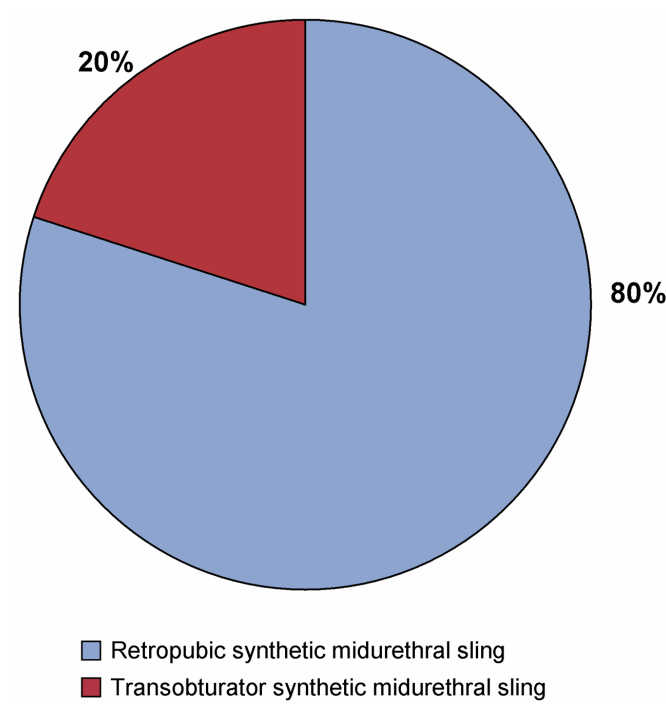

(d)

Figure 2. The most common prolapse procedures by compartment, as reported by fellows: (a) Procedures for apical prolapse; (b) Procedures for anterior compartment prolapse; (c) Procedures for posterior compartment prolapse; (d) Procedures for stress urinary incontinence (see following page).

for apical prolapse, anterior prolapse, posterior prolapse, stress urinary incontinence, and refractory urgency, frequency, and urge incontinence they expected to feel comfortable performing on completion of their fellowship. Other common urogynecologic procedures were also evaluated (e.g., pessary fitting, ureteral stent placement). Program directors were asked identical questions regarding the surgical comfort level of their graduating fellows, and the answers were compared. Significant differences were seen in responses to the following questions: "other" procedures for apical prolapse ("other" defined as apical procedures aside from uterosacral ligament suspension, sacrospinous ligament fixation, sacrocolpopexy, and transvaginal mesh kit), graft-rein- forced posterior colporrhaphy, rectus fascia sling, urethral bulking agent, bladder instillation, cystoscopic ureteral stent placement, and bowel surgery/repair (Figures 4 (a)-(f)). In all instances, a greater proportion of program directors reported that fellows would be comfortable performing these procedures upon graduation than the proportion reported by the fellows themselves. Training in laparoscopic and robotic surgery as part of fellowship curriculum was noted by $69.2 \%$ and $75.0 \%$ of fellows, respectively. The majority of programs required off-service rotations, with $89 \%$ requiring time with urology and colorectal surgery. Other rotations included gastroenterology, physical medicine and rehabilitation, geriatrics, plastic surgery, and gynecologic oncology. De- 


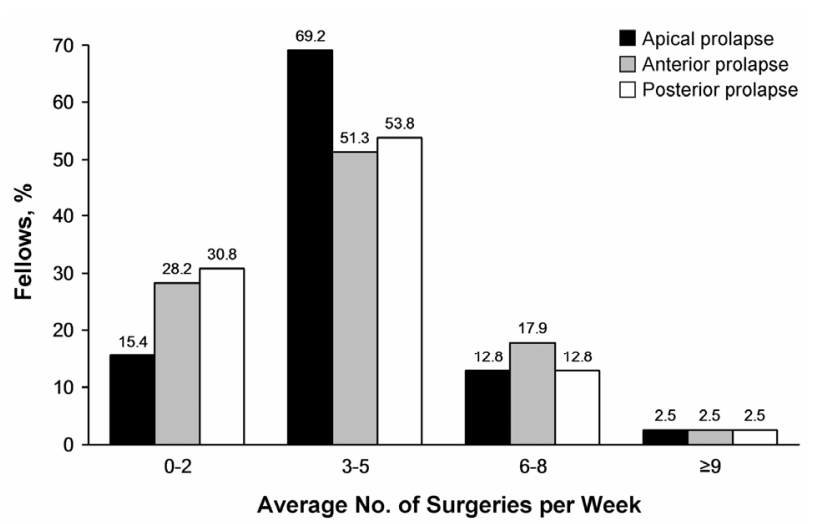

Figure 3. Description of the average number of surgeries performed by fellows per week.

spite no fellowship programs incorporating an intensive care unit rotation, $28 \%$ of fellowship directors believed that this rotation would be beneficial.

\subsection{Educational/Didactic Requirements}

Educational components beyond surgical training varied across fellowship programs, and program director responses were used for the evaluation of these components. Of the responding programs, $52 \%$ offered a master's degree as part of the fellowship. Formal education in statistics and epidemiology was reported in $100 \%$ and $89 \%$ of programs. Formal classes in research protocol development were offered at $63 \%$ of fellowships, with less common offerings including anatomy in $30 \%$ and medical ethics in $22 \%$ of programs.

\subsection{Post-Training Employment}

Similar expectations for employment after fellowship graduation were noted between fellows and program directors. Fifty-two percent of fellows and $44 \%$ of program directors anticipated fellows would pursue academic careers, while $40 \%$ of fellows and $52 \%$ of directors anticipated pursuit of a hybrid of academic and private practice. Only $8 \%$ of fellows and $4 \%$ of directors anticipated pursuit of private practice.

\subsection{Obstetric Call Coverage and Academic Productivity}

The survey's final questions addressed obstetrical call and anticipated publications. Just over half (52\%) of responding fellows provided obstetrical call during their fellowship. This service was an institutional requirement in $67 \%$, an institutional option in $9 \%$, and locum tenens in $29 \%$ of the programs. With respect to academic productivity, the median number of expected publications during fellowship was identical between fellows and program directors at 4 to 7 (answer options were $\leq 3,4$ -
7, $8-10$, and $>10$ ).

\section{DISCUSSION}

Graduate medical education has been met with many challenges in recent years, with changes affecting trainees at both residency and fellowship levels. Changing of resident duty hours, decreasing financial reimbursement, and continual strides to improve patient safety have made the challenge of teaching medicine, and in particular surgery, even harder. Such external influences have changed the current paradigm of medical and surgical education across nearly all specialties, with more emphasis being put on simulation and virtual surgery trainers. As the field of medicine becomes more subspecialized, residencies and fellowships must continue to maintain high-quality education.

The aim of this study was to evaluate surgical and nonsurgical aspects of training in FPMRS fellowships in the United States. We sought to determine similarities and differences in approaches to common problems of this area of medicine that are encountered by pelvic surgeons (e.g., pelvic organ prolapse, urinary incontinence). We also evaluated expected surgical competency on fellow graduation from the viewpoint of the student (fellow) and the teacher (fellowship program director). Published data are limited on this topic. In 2008, Kenton et al. [9] evaluated the comfort level of recent obstetrics and gynecology graduates in performing reconstructive pelvic surgery procedures on residency completion. They compared responses from graduates with the expectations of the residency director and found inconsistencies. Findings showed residency directors more often expected their graduates to feel comfortable performing various pelvic reconstructive surgery procedures independently than did the graduates themselves.

These results are similar to those found in the present study of FPMRS fellows and several urogynecologic procedures. The results included various techniques for apical suspension, graft-reinforced posterior colporrhaphy, rectus fascia sling, urethral bulking agents, cystoscopic ureteral stent placement, and bowel surgery and repair. Trends in laparoscopy continue to change in the field of urogynecology. We found that more fellows are getting trained in robotic surgery than traditional laparoscopy ( $75 \%$ vs $69 \%)$. Reasons for this finding were not investigated, but one can speculate that increased availability of the robotic surgical system has had a role in this change. Currently, many institutions are implementing a formal robotic surgery curriculum into gynecologic surgery education $[12,13]$.

Off-service rotation requirements varied among programs. Most included urology and colorectal surgery; however, variability was considerable in the time spent on these rotations, with a range from less than 2 weeks 


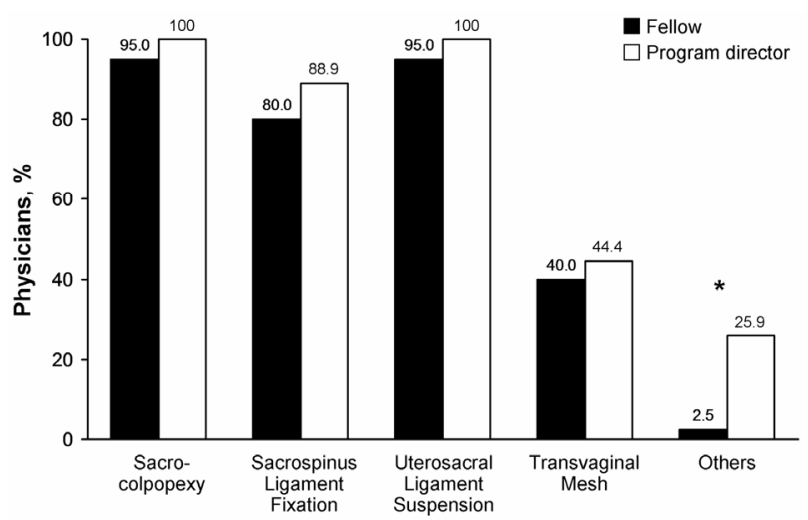

Apical Compartment Procedures

(a)

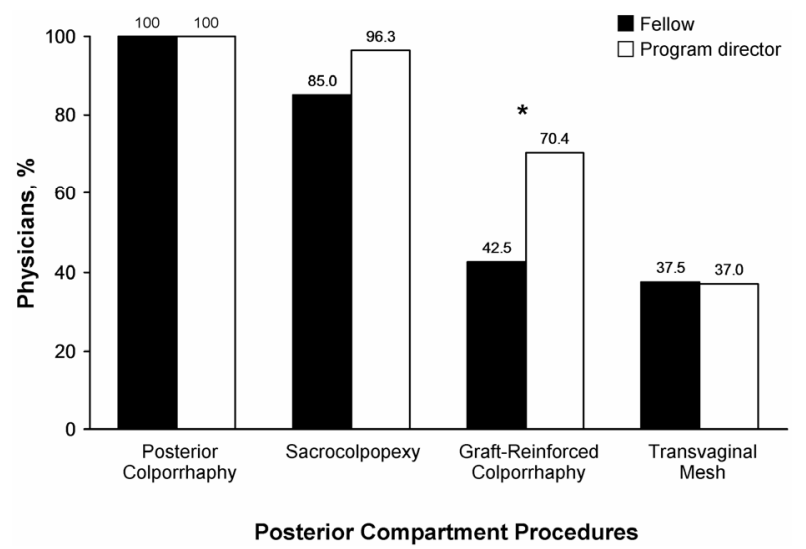

(c)

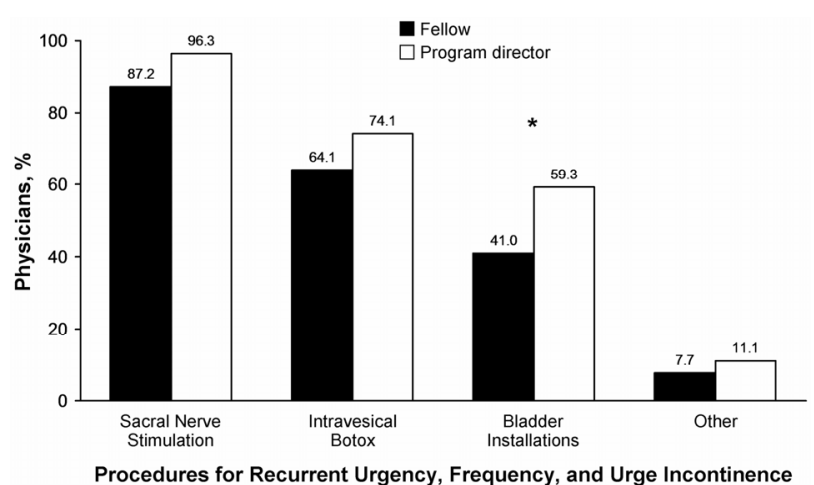

(e)

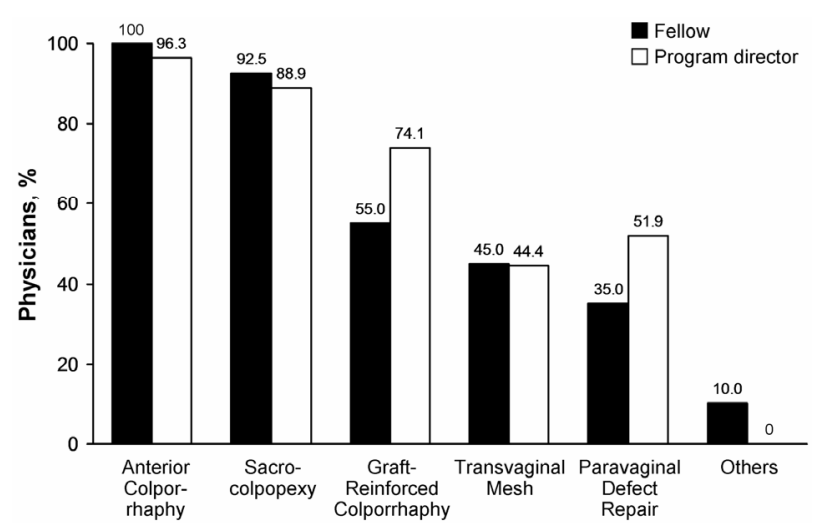

Anterior Compartment Procedures

(b)

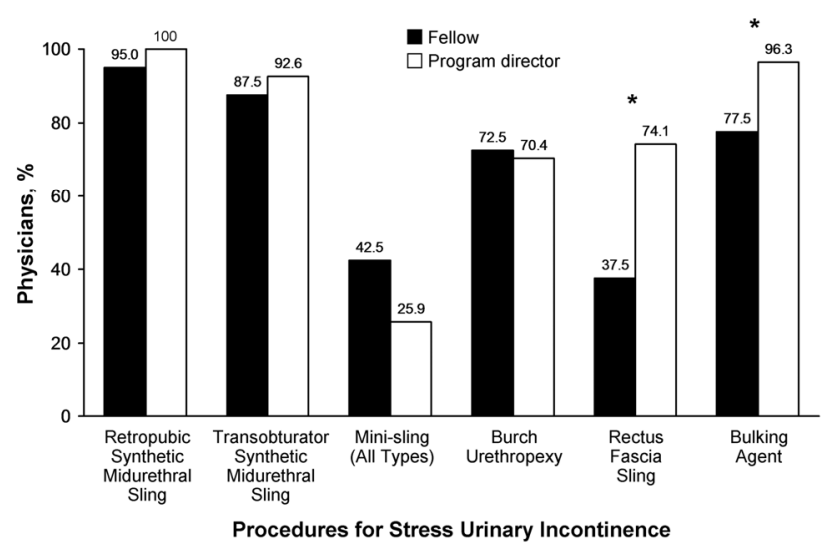

(d)

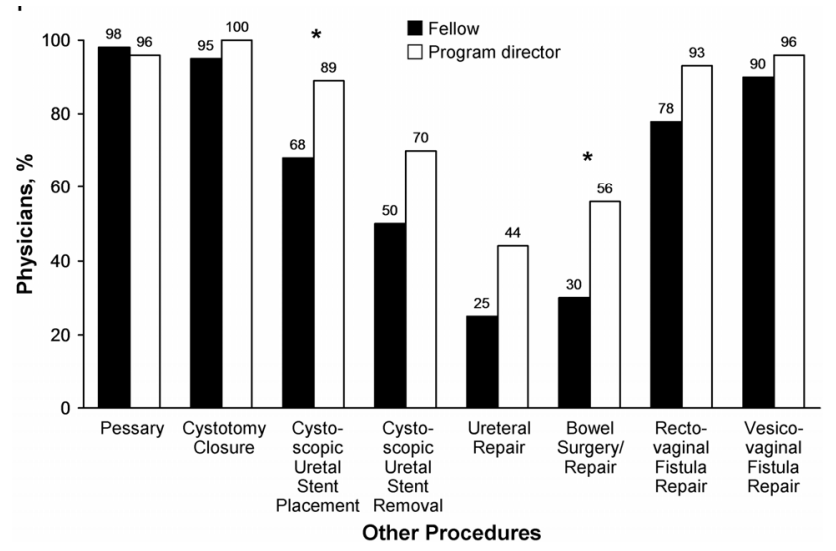

(f)

Figure 4. Perspectives of program directors vs fellows regarding expected competency in performing the procedures on completion of fellowship. (a) Apical prolapse; (b) Anterior compartment prolapse; (c) Posterior compartment prolapse; (d) Stress urinary incontinence; (e) Recurrent urinary urgency, frequency, and/or urge incontinence; (f) Other procedures. Asterisk indicates a statistically significant difference $(P<0.05)$.

to more than 9 weeks. Less common requirements included rotations in plastic surgery and gynecologic oncology. Although no responding programs had a rotation in intensive care medicine, $28 \%$ of program directors believed it would be beneficial for their fellows. Similar to other obstetrics and gynecology fellowships, FPMRS includes an emphasis on research and education. Most institutions required minimal classes in statistics and epidemiology, while other centers required a complement of academic courses that culminated in a master's degree. Pelvic anatomy was offered at only $30 \%$ of responding institutions, despite changing trends in anat- 
omy education during medical school and residency [14].

We found similarities among training programs as well. Vaginal apex suspension was accomplished by uterosacral ligament suspension or sacrocolpopexy in more than $75 \%$ of programs. Most programs used traditional colporrhaphy for the management of posterior compartment prolapse. Midurethral slings were the only procedures recorded for treatment of stress urinary incontinence, with the majority using retropubic, synthetic slings.

The FPMRS stands at a crossroads of contemporary medical change because it is the first obstetrics and gynecology fellowship to receive accreditation from the Accreditation Council of Graduate Medical Education instead of ABOG.

General requirements for surgical and nonsurgical education must be met in order to have a formalized fellowship; however, there exists much variability in what graduates are being taught. This variability extends from surgical approaches to pelvic prolapse repair to formal class work in medical ethics. A more thorough understanding of what current fellows and program directors believe are the strengths and weaknesses of their programs should be achieved. It also is necessary to understand the variations in surgical and non-surgical education, because this understanding will allow us to improve the training of future fellows [15]. Universally accepted educational objectives and program requirements are also necessary to formalize a written and oral board examination.

Study strengths include a novel evaluation of the FPMRS fellowship from the perspective of the fellow and the fellowship director, because prior research had been focused at the residency level only. There are no current available data assessing surgical and non-surgical teaching in accredited FPMRS fellowships. Also, the study findings provided insight into the clinical and nonclinical aspects of fellowship, both of which are important for a complete understanding of the state of contemporary training. Weaknesses include the small numbers of responses, particularly with the fellows and urology-based programs. However, because fellows and directors were given the option of identifying their current program in the final question of the survey, it is known that at least 21 fellowship programs were represented by the fellows responding, which is greater than $50 \%$ of the accredited programs.

\section{CONCLUSION}

As FPMRS journeys into a new era of accreditation and formalized training, a better understanding of the current state of fellowship education and the variation of practice and educational opportunities nationwide is necessary to establish the best-possible teaching and learning envi- ronment for future trainees.

\section{REFERENCES}

[1] Goff, B.A. (2008) Changing the paradigm in surgical education. Obstetrics \& Gynecology, 112, 328-332. doi:10.1097/AOG.0b013e3181802163

[2] Karram, M.M. (2008) The future of surgical training in the field of urogynecology and female pelvic floor surgery. International Urogynecology Journal and Pelvic Floor Dysfunction, 19, 1591. doi:10.1007/s00192-008-0746-0

[3] Julian, T.M. and Rogers, R.M. (2006) Changing the way we train gynecologic surgeons. Obstetrics \& Gynecology Clinics of North America, 33, 237-246. doi:10.1016/j.ogc.2006.01.005

[4] Walter, A.J. (2006) Surgical education for the twentyfirst century: Beyond the apprentice model. Obstetrics \& Gynecology Clinics of North America, 33, 233-236. doi:10.1016/j.ogc.2006.01.003

[5] Beard, J.D., Marriott, J., Purdie, H. and Crossley, J. (2011) Assessing the surgical skills of trainees in the operating theatre: A prospective observational study of the methodology. Health Technology Assessment, 15, 1-162.

[6] Schreuder, H.W., Oei, G., Maas, M., Borleffs, J.C. and Schijven, M.P. (2011) Implementation of simulation in surgical practice: Minimally invasive surgery has taken the lead: The Dutch experience. Medical Teacher, 33, 105-115. doi:10.3109/0142159X.2011.550967

[7] Schimpf, M.O., Feldman, D.M., O'Sullivan, D.M. and LaSala, C.A. (2007) Resident education and training in urogynecology and pelvic reconstructive surgery: A survey. International Urogynecology Journal and Pelvic Floor Dysfunction, 18, 613-617. doi:10.1007/s00192-006-0203-x

[8] Sultana, C.J., Kenton, K., Ricci, E. and Rogers, R.G. (2007) The state of residency training in female pelvic medicine and reconstructive surgery. International Urogynecology Journal and Pelvic Floor Dysfunction, 18, 1347-1350. doi:10.1007/s00192-007-0329-5

[9] Kenton, K., Sultana, C., Rogers, R.G., Lowenstein, T. and Fenner, D. (2008) How well are we training residents in female pelvic medicine and reconstructive surgery? American Journal of Obstetrics \& Gynecology, 198, 567. e1-e4.

[10] Drutz, H.P. (2010) IUGA guidelines for training in female pelvic medicine and reconstructive pelvic surgery (FPM-RPS): Updated guidelines 2010. International Urogynecology Journal, 21, 1445-1453.

[11] The American Board of Obstetrics and Gynecology, Inc. and The American Board of Urology, Inc. (2011) General and special requirements for graduate medical education in the subspecialty of female pelvic medicine and reconstructive surgery.

http://www.med.uc.edu/obgyn/Libraries/Documents/GSR -FPM 4-11 Internet Version.sflb.ashx

[12] Lee, P.S., Bland, A., Valea, F.A., Havrilesky, L.J., Berchuck, A. and Secord, A.A. (2009) Robotic-assisted lapa- 
roscopic gynecologic procedures in a fellowship training program. Journal of the Society of Laparoendoscopic Surgeons, 13, 467-472.

doi:10.4293/108680809X12589998403921

[13] Geller, E.J., Schuler, K.M. and Boggess, J.F. (2011) Robotic surgical training program in gynecology: How to train residents and fellows. Journal of Minimally Invasive Gynecology, 18, 224-229.

doi:10.1016/j.jmig.2010.11.003
[14] Heisler, C.A. (2011) Importance of adequate gross anatomy education: The impact of a structured pelvic anatomy course during gynecology fellowship. Anatomical Sciences Education, 4, 302-304. doi:10.1002/ase.235

[15] Blaivas, J.G. and Appell, R.A. (2000) Female pelvic medicine and reconstructive surgery fellowships. Neurourology and Urodynamics, 19, 635-636. doi:10.1002/1520-6777(2000)19:6<635::AID-NAU1 $>3.0$ .CO;2-4 